RESENHA 



\section{JUNQUEIRA, Mary Anne. Velas ao mar: U.S. Exploring Expedition (1838-1842). A viagem científica de circum-navegação dos norte-americanos. São Paulo: Intermeios, 2015.}

Valdir Donizete dos Santos Junior*

Em tempos de globalização, quando, com raríssimas exceções, as mais diversas partes do mundo, das mais cosmopolitas às mais recônditas, se veem conectadas e interligadas pelas tecnologias de ponta nas comunicações e nos transportes, a primeira metade do século XIX apresenta-se como uma época ambígua: tão distante e, ao mesmo tempo, tão próxima de nós, de nossas vivências, do que somos e do que pensamos.

Distante, pois a correspondência epistolar, os diários manuscritos e as longas viagens a vapor parecem estar há anos-luz das comunicações informatizadas, dos aparelhos eletrônicos de última geração e das rápidas viagens aéreas que cortam os céus e mobilizam pessoas em todos os continentes. Próxima, uma vez que o período entre as últimas décadas do século XVIII e as primeiras do século XIX marca o advento de um momento histórico do qual ainda, de certa forma, fazemos parte. Durante esses anos, as então recentes inovações da indústria, especialmente o advento da energia a vapor, facilitaram o trânsito em águas até então desconhecidas pelo Ocidente e encurtaram as distâncias entre as várias partes do planeta.

\footnotetext{
"Professor de Ensino Básico, Técnico e Tecnológico do Instituto Federal de São Paulo (Campus Jacareí) e Doutorando do Programa de Pós-Graduação em História Social pela Universidade de São Paulo - USP. E-mail: valdirdsjr@gmail.com.
} 
JUNQUEIRA, Mary Anne. Velas ao mar: U.S. Exploring Expedition...

A tais transformações técnicas somava-se o racionalismo ilustrado tão exaltado pelo liberalismo do século XIX, que buscou esquadrinhar, classificar e catalogar tudo o que de novo fosse encontrado pelas potências ocidentais, construindo um conjunto de saberes que ditava hierarquias e incitava desejos imperiais. Tratava-se de um novo capítulo - um dos mais importantes - do processo de interligação de toda a superfície do globo terrestre, que se iniciara com as navegações ibéricas do século XV e que no século XIX vivenciava seu auge.

É sobre esse contexto de intensas transformações econômicas, sociais, culturais, políticas e tecnológicas que evidenciavam o avanço do capitalismo e da modernidade, ainda marcadamente ocidentais e, em grande medida europeus, que se debruça Velas ao mar: U.S. Exploring Expedition (1838-1842), a viagem científica de circum-navegação dos norte-americanos, o instigante e fundamental trabalho da historiadora brasileira Mary Anne Junqueira. Resultado de sua Tese de Livre-Docência em História dos Estados Unidos, defendida em 2012, na Faculdade de Filosofia, Letras e Ciências Humanas da Universidade de São Paulo, esse livro apresenta ao público brasileiro, alicerçando-se em sólida pesquisa acadêmica, a U.S. Exploring Expedition, primeira viagem científica de circum-navegação do globo promovida pelos Estados Unidos. Executada pela Marinha norte-americana (U.S. Navy) entre 1838 e 1842, a missão foi comandada pelo genioso e polêmico capitão Charles Wilkes (1798-1877), autor dos cinco volumes da narrativa de viagem que serve como fio condutor do trabalho.

Trilhando as intersecções entre o mundo das viagens, a discussão científica e os interesses geopolíticos em jogo na primeira metade do Oitocentos, Velas ao mar apresenta, de início, uma dupla importância ao pesquisador dedicado à História das Américas, especialmente aos que se debruçam sobre o século XIX, qual seja, sua densa reflexão teórico-metodológica e sua originalidade temática.

Acerca do primeiro aspecto, Junqueira, estudiosa de temáticas e autores da chamada teoria pós-colonial, dialoga com referências importantes dessa seara, como Dipesh Chacrabarty, Mary Louise Pratt e o fundamental Edward Said. Discute com Chacrabarty, por exemplo, a necessidade de tirar a Europa do "centro" das análises 
acadêmicas; com Pratt, a existência de trocas, mesmo que assimétricas, entre colonizadores e colonizados nas chamadas "zonas de contato"; e com Said, a construção de saberes e conhecimentos como fatores de afirmação e dominação imperial. Merece destaque especial sua leitura do historiador argentino radicado nos Estados Unidos, também interlocutor da teoria pós-colonial, Ricardo Salvatore, referência básica que se evidencia nas linhas e entrelinhas dos três primeiros capítulos de Velas ao mar. Discutindo a constituição de "lugares de saber", Junqueira defende, acompanhando Salvatore, a existência de uma tensão latente entre a circulação transnacional de conhecimentos científicos, intelectuais ou técnicos e o processo de afirmação dos Estados nacionais no século XIX. Dito de outra maneira, a perspectiva transnacional, atualmente em voga na historiografia, nem sempre supera, mas frequentemente convive com o paradigma nacional.

Ainda em termos teórico-metodológicos, a autora reserva o quarto capítulo de seu trabalho exclusivamente a uma reflexão sobre a utilização dos relatos de viagem como fonte para o historiador. Para além de um mero balanço historiográfico, Junqueira aponta para a variedade desses textos e alerta para os cuidados que o pesquisador deve ter ao trabalhar com esse material. De acordo com a estudiosa, é preciso estar atento ao local de onde fala o viajante, ao seu universo cultural, ao período em que escreveu seu texto em relação ao período em que o publicou, à forma que escolheu para elaborá-lo (narrativa, carta, memória, diário etc.) e ao público que buscou cativar. Além dessas indicações metodológicas, a autora trava diálogo com a crítica literária, concebendo uma instigante reflexão sobre os relatos de viagem como um "gênero híbrido". Partindo dessa premissa, entende esse documento como sendo essencialmente múltiplo, capaz de ser lido de distintas maneiras por pessoas e em tempos diversos, e cujas vozes, estilos e formas evidenciam grande polissemia.

A respeito de sua originalidade temática, Velas ao mar destaca-se em alguns aspectos. Primeiramente, a U.S. Exploring Expedition, curiosamente, não é, como destaca a autora, a despeito de sua importância na História dos Estados Unidos, uma expedição que tenha sido alvo de maciços estudos, especialmente de pesquisas 
JUNQUEIRA, Mary Anne. Velas ao mar: U.S. Exploring Expedition...

acadêmicas de fôlego. Velas ao mar é, portanto, o primeiro trabalho sobre essa desconhecida empreitada nos marcos da investigação historiográfica brasileira ${ }^{1}$.

Em termos estruturais, o livro de Mary Anne Junqueira é composto por duas partes. Os três capítulos que formam a primeira seção do trabalho ("Em nome da ciência: para compreender a U.S. Exploring Expedition”) preparam o terreno para a análise propriamente dita da fonte. Inicialmente, insere a expedição comandada por Charles Wilkes em um contexto mais amplo das viagens de circum-navegação levadas a cabo por diversos países entre as décadas finais do século XVIII e as iniciais do XIX. Com o aprimoramento das técnicas de navegação e a crescente importância do Oceano Pacífico e dos grandes contingentes populacionais asiáticos para o comércio internacional, conhecer e mapear os mares era de suma importância para a obtenção de vantagens econômicas e geopolíticas. Nesse sentido, os Estados Unidos colocavam-se, ao se lançarem nessa empresa, em compasso e, ao mesmo tempo, em competição com países como a Inglaterra, a França e a também emergente Rússia, como pretendentes ao poder que o conhecimento sobre o mundo poderia propiciar.

Junqueira discute ainda, nos dois capítulos seguintes, dialogando com a História das Ciências e dos saberes científicos, como a expedição se circunscreveu em um quadro mais geral de definição de padrões internacionais acerca da navegação no globo terrestre. Nesse sentido, a autora nos mostra, seguindo Salvatore, que, na tensão entre a circulação transnacional e os interesses especificamente nacionais, uma vasta gama de conhecimentos, como as longitudes da Terra, as coordenadas geográficas e o mapeamento náutico, entendidos atualmente por muitos como dados puramente técnicos, foram fruto de intensa disputa geopolítica, da qual os norte-americanos se mostravam bastante propensos a participar. Constituiu-se, dessa maneira, nos marcos da primeira metade do século XIX, um quadro em que os Estados Unidos - que buscavam seu lugar no mundo - estabeleceram uma relação ambígua em relação à Europa, oscilando entre a admiração e a concorrência.

A seção final do trabalho (Cultura imperial: as Américas na narrativa de viagem de U.S. Exploring Expedition), composta por 
quatro capítulos, debruça-se mais especificamente sobre o mundo dos relatos de viagem: refletindo teórica e metodologicamente sobre esse tipo de fonte (capítulo 4), analisando de maneira mais detida a narrativa escrita pelo capitão da U.S. Exploring Expedition, Charles Wilkes, (capítulos 5 e 6 ) e cotejando, ao lado deste, relatos deixados por dois outros membros da tripulação da expedição, o marinheiro Charles Erskine e o aspirante a oficial William Reynolds (capítulo 7).

Sobre os cinco volumes da narrativa de Wilkes, a historiadora destaca sua inserção em um conjunto maior de textos que formam o relato oficial da viagem, composto originalmente por vinte e três tomos que versam sobre assuntos diversos, como etnologia, filologia, meteorologia, botânica, hidrografia, os aspectos mais diversos da zoologia e a temática das "raças do homem". Junqueira ressalta os embates e as tensões expostas no processo de escrita desse documento oficial, já que por seu caráter polêmico e por ter sido acusado de cometer diversos excessos ao longo da viagem, Charles Wilkes não era considerado por muitos a pessoa mais indicada para esse encargo. Como se evidencia pela leitura do trabalho, não somente o capitão foi o autor da descrição da viagem, como também a usou para se defender de seus críticos.

Velas ao mar reserva um de seus capítulos para uma análise sobre como Wilkes descreveu as Américas. Para tanto, a autora realiza um instigante debate sobre a questão da raça no relato e principalmente sobre a maneira como o capitão norte-americano concebia a ideia de "raça anglo-saxônica". Inserida em uma reflexão alicerçada em uma bibliografia em língua inglesa especializada no tema, Junqueira discute a construção de uma retórica que concebe a superioridade civilizacional desse grupo formado por britânicos e norte-americanos em relação aos demais povos do planeta. Balizado por esse discurso, Wilkes afirmava a inferioridade dos povos que na América haviam sido colonizados por espanhóis e portugueses. $\mathrm{O}$ capitão não se utilizava para se referir a estes últimos, como era de se esperar, de expressões relacionadas à ideia de "latinidade", como América Latina ou raças latinas, pois se o "anglo-saxonismo" da América do Norte já estava consolidado na época da expedição, o mesmo não se pode dizer da reinvindicação da "latinidade" por 
parte dos ibero-americanos, que somente iria se estabelecer de fato na retórica do continente a partir da década de 1850 .

Mary Anne Junqueira encerra seu trabalho analisando, ao lado das narrativas de Wilkes, outros dois relatos produzidos por membros da expedição do U.S. Exploring Expedition: o marinheiro Charles Erskine e o aspirante a oficial William Reynolds. Para além de considerações sobre as relações pessoais e hierárquicas, bem como os costumes e as práticas cotidianas de tais viagens, é possível afirmar que a principal contribuição desse capítulo para o conjunto do trabalho seja a constatação de que a cultura imperial presente nas ideias norte-americanas já na primeira metade do século XIX não era privilégio de suas elites, mas era compartilhada pelas diversas classes sociais. A despeito das desavenças que esses dois outros personagens pudessem ter tido com Wilkes durante a viagem, não divergiam de seu capitão em um aspecto: a concepção da superioridade dos anglo-saxões em relação aos demais povos do continente americano.

Finalmente, é preciso mais uma vez destacar que Velas ao mar representa uma importante contribuição não somente para aqueles que estudam os relatos de viagem e a história das Américas no século XIX, mas para todos que desejam ter acesso a um trabalho de pesquisa sólida e reflexão acadêmica densa. Enfim, Mary Anne Junqueira oferece novamente elementos para o conhecimento da História dos Estados Unidos no Brasil, demonstrando que, já em seu processo de formação nacional na primeira metade do Oitocentos, os norte-americanos ambicionavam um lugar de destaque entre as nações mais poderosas do mundo e enunciavam precocemente uma retórica imperial que, como se sabe, tem justificado, desde meados do século XIX, a presença dos Estados Unidos em diversas regiões do globo, não necessariamente de modo cordial e pacífico. 


\section{Notas}

${ }^{1}$ Possivelmente, o trabalho mais conhecido sobre a missão, inclusive com tradução brasileira, seja Mar de Glória: viagem americana de descobrimento (Companhia das Letras, 2005), do historiador estadunidense Nathaniel Philbrick. Voltado para um público mais amplo que o meramente universitário, o livro de Philbrick, a despeito de lançar luz e fornecer dados sobre a viagem e seus desdobramentos, não prima, muitas vezes, na opinião de Junqueira, pela crítica, adotando mesmo um caráter laudatório em relação ao seu objeto de análise.

Recebido em: 03/04/2017

Aprovado em: 05/08/2017 
